\title{
Una propuesta alternativa a la política monetaria
}

\author{
Econ. Pablo Rivas Santos
}

\section{RESUMEN}

Aun cuando los procesos inflacionarios en el mundo se han moderado, la inflación sigue preocupando. La inflación está asociada a aumentos indebidos de la masa monetaria. Estos aumentos tienen origen político. Por ello, elementos institucionales se incorporan al análisis de la inflación. Entre estos elementos están los bancos centrales de reserva (BCR) independientes, los que se perciben como un elemento indispensable en el control de la inflación. Pero, aun así, un ente de este tipo, independiente, no es una garantía institucional de inflación baja o nula.

Si no fuera por la excesiva interferencia del gobierno en el sistema monetario, no tendríamos ningún ciclo económico y ningún período de depresión. Los ciclos económicos son el fruto de equivocaciones deliberadas hechas por las políticas del gobierno. El error es la creación de un monopolio donde la base monetaria es controlada por el gobierno. Dado que todos los bancos generan dinero secundario, que es redimible en la base monetaria, se tiene un sistema que nadie pueda controlar. Es el monopolio del gobierno en la emisión de dinero el que en última instancia es responsable.

La inflación genera desempleo al asignar a la gente empleos que solo existen porque la demanda de determinados productos sube temporalmente, y estos empleos desaparecen apenas se detiene el aumento de la cantidad de dinero. 


\section{Pablo Rivas Santos}

Para evitar la inflación, la política monetaria debe conducirse con la meta de mantener la estabilidad del valor del dinero. Las fuerzas del mercado pueden ajustarse para lograr esa estabilidad. Se debe poner la emisión de dinero en manos de instituciones cuyo negocio dependa de su éxito en mantener estable el valor del dinero que emiten.

Palabras clave: Procesos inflacionarios, ciclos económicos, política monetaria, dinero secundario.

\section{ABSTRACT}

While inflation processes in the world are moderate, inflation remained a concern. Inflation is associated with inappropriate increases in the money. These increases are politically motivated. Therefore, institutional elements are incorporated into the analysis of inflation. Among these elements are independent BCRS, which are perceived as an essential element in controlling inflation. But an independent BCR is not an institutional guarantee of zero or low inflation.

If not for the excessive government interference in the monetary system, there would be no business cycle and no period of depression. Economic cycles are the result of mistakes made by deliberate government policies. The mistake is to create a monopoly where the money is controlled by the government. Since all banks create money side, which is redeemable in the monetary base, is a system that nobody can control. It is the government's monopoly on the issuance of which is ultimately responsible.

Inflation generates unemployment andalusia assign people to jobs that exist only because the demand for certain products go up temporarily, and those jobs disappear just stop increasing the amount of money.

To avoid inflation, monetary policy must be conducted with the goal of maintaining stability in the value of money. Market forces can be adjusted to achieve that stability. We should put the issue of money in the hands of institutions whose business depends on its success in keeping the value of money they emit.

Keywords: Inflation, business cycles, monetary policy, money second.

\section{INTRODUCCIÓN}

Para Keynes, se debe aceptar los salarios tal como son y ajustar la política monetaria a la estructura salarial existente. Sin embargo, ignoró que los sindicatos sabían que el 


\section{Una propuesta alternativa a la política monetaria}

gobierno estaba obligado a corregir el efecto de la política sindical, y así se genera una espiral inflacionaria: los sindicatos presionan hacia arriba los salarios, y el gobierno tiene que proporcionar el dinero suficiente para mantener el nivel de empleo a ese nivel de salarios, y esto conduce a una espiral inflacionaria. El fenómeno surge de la consideración de Keynes que en el corto plazo no es posible hacer nada respecto a la rigidez salarial.

Los precios son un instrumento de comunicación y guía que incorporan más información de la que poseemos directamente. Si se necesita de los precios (incluyendo el precio del trabajo) para guiar a la gente a que vaya por donde sea necesario; se debe disponer de una distribución del ingreso que se haga sobre la base del principio del mercado. El desarrollo económico se alcanza usando tecnología, innovación e información de precios.

El desarrollo económico que florece de la semilla de la economía de mercado no debe producir burócratas y administradores que desplacen a innovadores y empresarios que han hecho todo lo posible para alcanzar el desarrollo económico.

El tejido social sobre el que reposa la economía de mercado es la aceptación y respeto a la propiedad privada.

\section{LA POLÍTICA MONETARIA ES EL JUEGO DE DADOS DEL BCR}

El ciclo económico es inseparable de la política monetaria, lo cual significa que las fases del ciclo económico son inseparables de la política monetaria. Toda política monetaria altera los precios relativos, lo cual conduce a una mala asignación de los factores de producción. La política monetaria expansiva hace que a corto plazo la tasa de interés sea menor de la que hubiera sido en ausencia de esa expansión y aparenta que hay mayor ahorro disponible. Esa tasa de interés artificialmente reducida induce a que se invierta en proyectos aparentemente atractivos, pero que en verdad son antieconómicos.

Son proyectos de inversión en bienes en los que el proceso productivo requiere más tiempo. Pero como en realidad no hay un mayor ahorro disponible, las acciones subsiguientes en el mercado restablecen las relaciones de la estructura verdadera del capital disponible. 


\section{Pablo Rivas Santos}

Esto aclara el proceso de inversión ineficiente; mostrando que quienes sobre-invirtieron en áreas antieconómicas, deben cancelar operaciones como consecuencia de haber sub-invertido en otras áreas. La primera etapa de inversión ineficiente se denomina "boom", y la segunda etapa de saneamiento se denomina "crac". Este proceso es consecuencia de reducciones artificiales de la tasa de interés y de distorsiones en toda la estructura de precios relativos. Si se pretende disimular la depresión con: subsidios a empresas y actividades quebradas, inflexibilidad de salarios, $e$ intervenciones estatales adicionales en el mercado financiero y bancario; la situación se agravará ya que habrá que tener en cuenta los efectos nocivos que acarrean tales medidas; y que se prolongará el período de ajuste debido a la acumulación de despilfarros adicionales de capital.

\subsection{Monopolio estatal}

Se debería eliminar el monopolio estatal de la moneda, es decir la prerrogativa que otorga a los gobiernos la facultad monopólica de ocuparse de la moneda.

No es conveniente otorgar patente monopólica a la moneda porque se ve a través de la historia cómo los gobiernos han explotado sistemáticamente el monopolio de la moneda en beneficio propio y en perjuicio de la gente.

\subsection{Competencia monetaria}

El curso forzoso es un privilegio para los gobiernos, que se traduce en un perjuicio para la gente. Si se elimina el curso forzoso; las partes en un contrato acordarán la moneda que consideren mejor para salvaguardar del mejor modo sus respectivos intereses. La eliminación del curso forzoso no es obstáculo para que el gobierno decida en qué moneda se pagarán los impuestos; aunque cada persona hará sus arreglos contractuales en base a la moneda que le merezca mayor confianza y, así, las monedas que ofrezcan los atributos más atractivos a criterio de la gente serán las más usadas. En este contexto, los tribunales, en sus fallos, establecen los tipos de monedas con los que se deben cancelar deudas.

Preservar las características centrales de la moneda (que se desprenden del uso como medio de cambio), la unidad de cuenta, pagos futuros y liquidez se logra a través de un sistema competitivo y abierto. 


\section{Una propuesta alternativa a la política monetaria}

Se ha pretendido desacreditar la competencia de monedas a través de una interpretación errada de la Ley de Gresham. Esta ley enseña que la mala moneda desplaza a la buena siempre que se establezca control de cambios. Esta ley no se aplica cuando hay libertad de cambios. Son diversos los pretextos para no permitir la libertad de contratación, pero todos apuntan a defraudar a la gente, ya que la historia de la inflación es la historia de la inflación generada por los gobiernos para su propio provecho. Esto es la base del sistema keynesiano que reitera y agrava errores en materia monetaria y laboral a lo que se han agregado visiones como la "inflación de costos", como si se pudiera inflar los precios sin una dosis adicional de moneda.

Debe abandonarse la política monetaria "de la fina sintonización" y de "la cantidad óptima de dinero". Para lograr este objetivo debe realizarse "una enorme tarea educativa" apuntando a eliminar el monopolio estatal de la moneda; ya que la inestabilidad de las economías es una consecuencia de excluir del mercado la moneda (que es el mecanismo estabilizador del mercado).

\section{CAUSAS ENDÓGENAS Y EXÓGENAS}

Los precios se modifican según se modifiquen los gustos, preferencias, modas, accidentes climáticos y cualquier otro suceso que nazca y se desarrolle dentro del mercado. Esta modificación de los precios se llama fenómenos endógenos.

Cuando el gobierno emite o contrae dinero; los precios se alteran debido a una decisión política. Se trata de fenómenos exógenos. Aquella alteración de precios mal-

guían a los operadores económicos, lo cual se traduce en consumo de capital que a su vez conduce a una reducción de salarios e ingresos reales.

La definición de inflación "el aumento general de precios", tiene 2 defectos:

$1^{\circ}$ Si el aumento de precios es general, no habría problema con la inflación. El salario es también un precio, y si aumenta al mismo ritmo que el resto de precios el problema se circunscribe a modificar la cantidad de dígitos en las calculadoras, y las columnas en los libros de contabilidad, o a encontrar nuevos procedimientos para transportar mayores volúmenes de dinero. Si todos los precios aumentaran al unísono, no se producirían los desequilibrios característicos de la inflación. 


\section{Pablo Rivas Santos}

Cuando la nueva moneda se esparce por el mercado, toca los distintos sectores en distintos momentos, lo cual altera los indicadores de mercado, en distintas proporciones $y$ en distintos momentos.

$2^{\circ}$ La inflación no es el aumento de precios. La inflación es la expansión de la moneda debido a fenómenos exógenos. El aumento de precios es el efecto de la inflación. Se reserva la expresión inflación para las alteraciones que suceden debido a fenómenos exógenos.

Cuando decimos "el mercado requiere o el mercado decide" nos referimos a específicas acciones de específicos individuos, a arreglos contractuales libres y voluntarios entre las partes.

\subsection{Banco Central de Reserva}

El BCR decide entre 3 caminos: ¿A qué tasa expande, a qué tasa contrae o si deja inalterada la masa monetaria? Cualquier decisión que adopte, distorsiona los precios.

Si expande al 7\%, se distorsiona los precios debido a la decisión política de expandir al $7 \%$.

Si contrae al $2 \%$, se distorsiona los precios debido a la decisión política de contraer al $2 \%$.

Si deja inalterada la masa monetaria; y la gente prefiere contar con mayor cantidad de dinero; se estará en un proceso deflacionario.

Si deja inalterada la masa monetaria, y la gente prefiere contar con una menor cantidad de dinero; se estará en un proceso inflacionario.

Si la masa monetaria que el BCR dejó inalterada, coincide con la masa monetaria que prefería la gente, la pregunta sería: ¿Para qué se entrometió el BCR si hizo lo mismo que hubiera hecho la gente sin tener que recurrir a la fuerza ni en gastos administrativos innecesarios? 


\section{Una propuesta alternativa a la política monetaria}

La única manera de saber qué es lo que la gente prefiere es dejarla que revele sus preferencias.

El BCR necesariamente se equivoca, no puede acertar en su decisión. Por esto es irrelevante el debate sobre si el BCR debe o no ser independiente; mientras tenga las atribuciones de autoridad monetaria se equivocará ya que sus decisiones serán distintas de las que adopta la gente y, como queda dicho, si son las mismas no tiene razón de existir.

Entonces, la diferencia entre el BCR dependiente y el BCR independiente está en que esta última cometerá los errores independientemente.

\subsection{Norma monetaria}

Los economistas podremos tener nuestras preferencias sobre la calidad y ventajas de una moneda sobre otra, pero lo que no podremos es imponer nuestras preferencias monetarias sobre la gente.

Se ha sugerido una norma monetaria (implementada legalmente) por la que se debería emitir a razón de un porcentaje anual que podría oscilar entre 3\% y 5\%. La decisión política de emitir (cualquiera sea el porcentaje) altera los precios como consecuencia de esa decisión y no proporciona información relevante a los operadores económicos el hecho que se anuncie con antelación ese porcentaje ya que los precios no galopan al son de determinado índice. Por más correlaciones que haya entre los ritmos de expansión monetaria y el comportamiento de los precios lo relevante es lo que sucede con los precios desde los primeros tramos del proceso inflacionario, y los consecuentes desajustes que provoca.

La pretensión de emitir al mismo ritmo que el aumento de la producción ignora los sucesos que hubieran ocurrido y que no ocurrieron, porque esa emisión los anuló. Manteniendo constantes los demás factores un aumento en la producción genera una tendencia a la baja en los precios, lo cual haría que aumenten las exportaciones, que se contraigan las importaciones y una serie de fenómenos que no ocurren porque esa emisión los anuló. Preguntar qué cantidad de dinero debería haber es lo mismo que preguntar qué cantidad de maíz debería producirse. La respuesta es la misma: lo que la gente prefiera. 


\section{Pablo Rivas Santos}

\subsection{Reserva monetaria}

Sean los sistemas monetarios y bancarios de mercado y de reserva al $\mathbf{1 0 0 \%}$. En cualquier caso, la cobertura de reserva es materia sobre la que deben acordar el banquero con sus clientes. Cualquiera sea el acuerdo, cada parte asume la responsabilidad de su contrato y los resultados en el mercado serán fruto de fenómenos endógenos. Es una posibilidad que el mercado requiera una reserva al 100\% en depósitos a la vista como si se tratara de un depósito en custodia, pero no es razonable imponer el nivel de reservas por encima (o por debajo) de lo que resuelvan las partes contratantes según sean sus propios intereses.

El dinero que posee una persona queda excluido del uso de otra persona (lo paga quien lo usa) y el servicio de liquidez que proporciona el dinero no lo puede consumir simultáneamente otra persona.

Es importante contar con un mercado monetario y bancario sin regulaciones para que la gente elija los tipos de moneda y las características de las operaciones financieras en las que desean embarcarse. Puede contarse con un proveedor o varios, según sean las circunstancias, lo cual variará según sean las modificaciones operadas en la tecnología pero lo decisivo es que el mercado se encuentre abierto para que la gente pueda contar con los necesarios reaseguros y resguardos, lo cual no sucede cuando se prohíbe la entrada a nuevos proveedores y se bloquea la competencia.

\section{CONCLUSIONES}

Si se quiere contar con un sistema monetario y financiero saneado, debe derogarse el curso forzoso y desregular todo el sistema.

La teoría interpreta y explica los nexos causales subyacentes en la realidad. Si la teoría es buena debe adoptarse, si es mala debe rechazarse. La libertad de utilizar la moneda que libremente se prefiera es la marca de un país libre. 


\section{Una propuesta alternativa a la política monetaria}

\section{BIBLIOGRAFÍA}

Buchanan, J. M. "Rights, Efficiency and Exchange: The Irrelevance of Transaction Costs”. En: Liberty, Market and State. Nueva York: Nueva York University Press, 1986 [1983].

Friedman, M. Moneda y desarrollo económico. Buenos Aires: Editorial El Ateneo, 1979 [1972].

Hayek, F. A. Desnacionalización del dinero. Londres: The Institute of Economic Affairs, 1976.

Hayek, F. A. Teoría Monetaria y los Ciclos económicos. Clifton, New Jersey: A. M. Kelley, 1975 [1929].

Keynes, J. M. A Tract on Monetary Reform. Londres: Harcourt, Brace, \& Co., 1923.

Klein, B. "The Competitive Supply of Money". Journal of Money, Credit and Banking, noviembre de 1975.

Rist, Charles. Historia de las doctrinas relativas al crédito y la moneda. Barcelona; Casa Editorial Bosch, 1945.

Robbins, Lionel. The Great Depression. Londres. MacMillan, 1934.

Rothbard, Murray. Man, Economy and State: A Treatise on Economic Principles. Los Angeles: Nash Pub., 1970.

Von Mises, L. La teoría del dinero y el crédito. Barcelona, Edit. Zeus, 1962.

Por Econ. Pablo Rivas Santos. Profesor de Economía e investigador del Instituto de Investigaciones Económicas de la Facultad de Ciencias Económicas de la Universidad Nacional Mayor de San Marcos 